\title{
Disseny i avaluació del programa d'intervenció psicosocial per promoure la integració intercultural en el context universitari cubà
}

\author{
Design and evaluation of the psychosocial intervention programme \\ to promote intercultural integration in the Cuban university context
}

Isaac Irán Cabrera Ruiz (Universidad Central "Marta Abreu" de Las Villas, Cuba)

Ángel Joel Méndez López (Universitat de València, Espanya). Lidia Ortí Salinas (Universitat de València, Espanya)

Cita bibliogràfica: Cabrera Ruiz, I.I., Méndez lópez, A.J., Ortí Salinas, L. (2022). Disseny i avaluació del programa d’intervenció psicosocial per promoure la integració intercultural en el context universitari cubà. Disjuntiva, 3(1), 35-44.

https://doi.org/10.14198/DISJUNTIVA2022.3.1.3

\section{Resumen}

En 2013, El present estudi va tenir com a objectiu dissenyar un programa d'intervenció psicosocial, per a la promoció de la integració intercultural en la Universidad Central "Marta Abreu" de Las Villas, des d'un enfocament historicocultural de les mediacions per la subjectivitat. La recerca és d'intervenció i continua un enfocament qualitatiu i interpretatiu. En aquest marc, es va realitzar una sistematització d'experiències i es va proposar un programa d'intervenció psicosocial. El programa integra els següents components: fonaments teoricometodològics psicosocials, estructura organitzativa i avaluació del programa. L'avaluació del programa, abans de la seva implementació, va correspondreal tipus d'avaluació qualitativa i externa. Va produir valoracions sobre les fortaleses i febleses del programa, així com recomanacions per a fer més efectiu el programa d'intervenció, en funció de les quals es van introduir modificacions.

\section{Palabras claves}

Cultura; interculturalitat; integració; subjectivitat; intervenció psicosocial.

\begin{abstract}
In 2013, The aim of this study was to design a psychosocial intervention programme for the promotion of intercultural integration at the Central University "Marta Abreu" of Las Villas, from a historical-cultural approach of mediations for subjectivity. The research is of intervention and follows a qualitative-constructive and interpretative approach. Within this framework, a systematisation of experiences was carried out and a psychosocial intervention programme was proposed. The programme integrates the following components: psychosocial theoretical and methodological foundations, the organisational structure and the evaluation of the programme. The evaluation of the programme, prior to its implementation, corresponded to the type of qualitative and external evaluation. It produced assessments of the strengths and weaknesses of the programme, as well as recommendations for making theintervention programme more effective, on the basis of which modifications were made.
\end{abstract}

\section{Key words}

Culture; interculturality; integration; subjectivity; psychosocial intervention.

I.I.Cabrera: https://orcid.org/0000-0001-9354-539X A.J. Méndez: https://orcid.org/0000-0001-6587-580X Correu electrònic de correspondència: orti_lidia99@hotmail.com (Lídia Ortí). 


\section{Introducció - revisió de literatura.}

La interculturalitat s'assumeix com el conjunt de processos polítics, socials, jurídics i educatius generats per la interacció de cultures en una relació de reconeixement mutu i intercanvis recíprocs; provocats per la presència, en un mateix territori, de grups amb orígens i històries diferents (Escarbajal, 2010). Aquesta realitat, ja quotidiana i comuna, ha estat atesa mitjançant l'assimilació, la fusió o el pluralisme com a models sociopolítics de gestió; ineficients a causa del seu rerefons homogeneïtzador que reafirma una cultura hegemònica i codifica la diferenciació en termes culturals, sense considerar paràmetres econòmics i de classe.

Les relacions interculturals, en el marc de la interacció grupal, es defineixen com a formes específiques de relació social entre individus que interactuen en qualitat de membres de grups culturalment diversos a partir de la reproducció i producció sociopsicològica de pertinences i exclusions grupals, mediades per factors històrics, econòmics i socioculturals (CabreraRuiz, Rodríguez-González, \& Rodríguez-Fleites, 2016). La formació de pertinences i exclusions grupals té lloc mitjançant processos sociopsicològics d'apropiació de classificacions culturalment disponibles que proveeixen als subjectes d'actereferencies; les quals els permeten reconèixer-se com a membres de categories socials (nacionalitat, ètnia, religió, gènere).

En les relacions interculturals queda accentuada la diversitat d'origen com a categoria de referència que esdevé en diferenciació entre endogrup i exogrup. D'aquesta manera, en esbossar la interculturalitat des de les relacions intergrupals, es pondera el procés d'identificació social, mediador de les dimensions relacionals i simbòlic-emocionals, en funció de la unió grupal. L'èmfasi en la diferència i l'omissió de la igualtat afavoreix els efectes excloents en detriment de la integració.

El caràcter de procés que adquireix la parella integració-exclusió és clar quan s'analitza la influència que pot tenir la discriminació en l'assumpció d'estratègies d'assimilació que donen lloc a una aparent integració social. La discriminació no sols és usada per a forçar l'exclusió en forma de segregació o marginació, sinó també per a forçar la inclusió en forma d'assimilació. Berry, Kim, Power, Young i Bujaki (1989, citat en Rodríguez, 2019) proposen una tipologia d'integració de grups minoritaris (quan aquests tenen la possibilitat de triar la manera de comprometre's en la relació intercultural) a partir de dues dimensions actitudinals: la importància que concedeixen a conservar la seva identitat cultural i l'obertura al contacte amb altres grups.

En el seu entrecreuament sorgeixen quatre possibles estratègies d'aculturació: assimilació (s'assumeixen els patrons culturals del grup dominant), segregació (es mantenen els patrons culturals propis i s'evita el contacte amb altres grups) marginació (existeix minso interès per mantenir els patrons culturals propis i establir contacte amb altres cultures) i integració (existeix l'interès tant en el grup majoritari com en el minoritari de mantenir les seves pròpies cultures i a participar en la societat). Quan el grup dominant imposa cert tipus de relacions o constreny les decisions del grup minoritari, es necessiten altres termes: fusionalisme, segregació, exclusió i multiculturalisme.

La integració ha de ser multidimensional i el seu correlat per als subjectes s'observarà en el nombre de contactes, participació en l'activitat social i un sentit de pertinença i identificació amb una comunitat (Brissette, Cohen \& Seeman, 2000; McMillan \& Chavis, 1986; Sarason, 1974, citats en Rodríguez, 2019). Això es manifesta en l'oportunitat d'inserirse en el procés de presa de decisions de manera activa i directa, no sols des de la posició de beneficiaris, sinó com a formuladors de solucions a la dinàmica de la vida quotidiana, sobre la base d'un sistema de valors i normes compartides.

La revisió d'experiències de transformació social entorn de la integració intercultural va permetre identificar pràctiques interculturals d'intervenció social i enfocaments d'intervenció psicosocial en la reducció de biaixos intergrupals. Entre les primeres es destaca l'educació intercultural que té com a grans nuclis la competència intercultural, l'equitat i inclusió social, les diferències individuals i la reforma del currículum (Aigualit, 2004). A més, es van identificar programes i pràctiques en l'àmbit comunitari, organitzacional i social (Alarcón \& Bustamante, 2007; Pinillos, 2012; Relinque \& Mora, 2016, citats en Rodríguez, 2019; Dietz, 2007; Carnacea, 2013). Els enfocaments d'intervenció psicosocials en la reducció de biaixos intergrupals poden dividir-se en dos àmbits: intragrupals i intergrupals. En les primeres es troba el treball amb exemplars contraestereotípics (Plant et al., 2009), les estratègies basades en la dissonància cognitiva (Festinger, 1957, citat en Rodríguez, 2019) i la promoció de l'empatia (Galinsky \& Moskowitz, 2000; Stephan \& Finlay, 1999). Com a estratègies intergrupals s'identifiquen les basades en la hipòtesi del contacte (Allport, 1954, citat en Rodríguez, 2019) i les basades en la teoria de la categorització social o estratègies sociocognitives (Tajfel \& Turner, 1979).

Dins de les ciències socials cubanes és insuficient el tractament de la diversitat cultural, a causa del predomini d'una concepció uniforme de la cultura com a consolidació del projecte social i de la identitat nacional; però aquesta concepció s'ha desestructurat enfront d'una realitat cada vegada més heterogènia (Rivero-Baxter, 2015). El tema cobra força, refereix aquesta autora, a causa dels efectes socials del reajustament de l'economia cubana: l'emergència de nous grups socials, diferències en el consum i l'increment d'associacions i institucions religioses i laiques. 
Lefont (2013) planteja l'existència d'estudis que aborden la diversitat cultural des dels processos migratoris i la seva influència en la història de la nacionalitat cubana. Cabrera (2011) destaca, com a referents a Cuba, a RodríguezMorel (1999), Fornet-Betancourt (2004, 2006), Expósito (2010), Monteagudo-Cásares (2010) i Gil (2011). En el marc de l'educació intercultural i d'un enfocament psicosocial de la interculturalitat des d'una concepció històric-cultural de la subjectivitat, es troba la producció científica de Cabrera (Cabrera, 2011; Cabrera, Rodríguez, \& Rodríguez, 2016; Pérez-Borroto, Cabrera, \& Rodríguez, 2020).

Aquests referents situen les relacions interculturals com a objecte de configuració de la subjectivitat social la qual, organitzada com a estereotips i prejudicis transmesos en processos socialitzadors, reprodueix l'exclusió mitjançant el reconeixement de la diferència que promou i justifica condicions reals de discriminació cap a determinats grups. D'aquesta manera s'explicita el caràcter mediador de la subjectivitat. Rodríguez i Cabrera (2019) van definir la mediació per la subjectivitat com les transicions, a manera de moviment dialèctic, de determinada contradicció social entre la seva configuració en els sistemes intersubjectius associats a l'acció del subjecte i les seves expressions en els sistemes de relació que des de la seva activitat viu.

Les formes dinàmiques de configuració subjectiva que mediatitzen les relacions intergrupals, definides per aquests autors, són estereotips, prejudicis i discriminació. Els estereotips constitueixen una configuració subjectiva de creences compartides atribuïdes a si mateix o altres categories o grups socials, als quals caracteritza de forma generalitzada i diferenciadora en nosaltres / els altres, alhora que justifiquen el comportament intergrupal.

Els prejudicis es defineixen com una actitud cap als membres d'un grup, les tendències avaluatives del qual són fonamentalment negatives. Definides des de la seva existència com a subjectivitat, les actituds són predisposicions i tendències de comportament que tenen un component únic: sentits subjectius avaluatius de la realitat social (Cabrera, Rodríguez, \& Álvarez, 2020). Aquests autors concorden que l'element més perniciós del prejudici és la discriminació; aquesta consisteix en conductes d'estigmatització i rebuig d'altres persones per pertànyer a uns certs grups socials (Allport, 1962; Oskamp, 1991; Morales \& Páez, 1996, citats en Rodríguez, 2019).

El resultat que es presenta a continuació pertany a la línia de recerca de les relacions interculturals des d'un enfocament psicosocial i una concepció històric-cultural de la subjectivitat; desenvolupada en la Universitat Central "Marta Abreu" de les Viles (en ho avanci UCLV). La recerca va tenir com a objectiu proposar un programa d'intervenció psicosocial per a la promoció de la integració intercultural en la UCLV, espai social on es treballa des de l'ultima dècada i on s'han presentat resultats diversos, sobre els quals es sosté el present article (Cabrera, Rodríguez, \& Álvarez, 2020).

La seva novetat científica va radicar en el disseny del programa d'intervenció psicosocial des d'un enfocament històric-cultural de les mediacions per la subjectivitat a manera de configuracions subjectives de la diferència i la identitat, les transicions recíproques expressades com a alternatives de subjectivació davant estereotips i prejudicis; així com les seves manifestacions en els sistemes d'acció i relació. La seva rellevància social va estar donada per la concepció de solucions a problemàtiques pràctiques identificades en el context de recerca.

\section{Metodologia}

La recerca es va adscriure al model de recerca interventiva proposat per Rothman i Thomas (1994) constituït per tres àrees: desenvolupament de coneixement, utilització de coneixement i disseny i realització d'intervencions. Es va orientar específicament en la tercera d'aquestes àrees.

Es va seguir un tipus de recerca qualitativa constructiu-interpretativa en el marc de la qual es va realitzar una sistematització d'experiències. Se segueix la proposta metodològica oferta per Jara (1994) des de la qual s'estructura la sistematització en cinc temps: el punt de partida (haver estat participant i tenir registres de l'experiència), les preguntes inicials (objectiu, objecte, eix de sistematització, fonts, procediments), la recuperació del procés viscut (reconstruir la història, ordenar i classificar la informació), la reflexió de fons (anàlisi, síntesi, interpretació crítica) i els punts d'arribada (formular conclusions i comunicar els aprenentatges). Es van considerar els criteris de validació del material sistematitzat proposats per De Armes (2014): pertinència social, factibilitat, aplicabilitat i rigor científic.

Els objectius de la sistematització van ser: 1) construir un model teòric comprensiu per a l'estudi de les mediacions per la subjectivitat en el procés integració-exclusió intercultural; 2) mostrar mediacions per la subjectivitat en el procés integració-exclusió intercultural. Els eixos de sistematització definits van ser: 1) evolució del model teòric de les 
mediacions per la subjectivitat en el procés integració-exclusió intercultural; 2) reproducció de l'exclusió i perspectives per a la integració intercultural.

Es va emprar com a mètode la recerca documental (Valls, 1999) i l'anàlisi de contingut (Ruiz-Olabuénaga, 1999). D'aquesta manera es van generar noves zones d'intel-ligibilitat des del model teòric que van permetre proposar un programa d'intervenció psicosocial.

El disseny del procés d'intervenció psicosocial va tenir com a fonaments les concepcions de Blanco i Valera (2007) i Ander-Egg (2003). Per a aquest últim autor, un programa fa referència a un conjunt organitzat, coherent i integrat d'activitats expressats en projectes de similar naturalesa. El projecte comprèn activitats interrelacionades i coordinades entre si que es realitzen per a aconseguir les metes i objectius. Les tasques són el conjunt d'accions que conformen una activitat.

\subsection{Mostra}

Es van seleccionar experiències desenvolupades en la UCLV, institució educativa cubana del nivell d'educació superior. Compte, des de 1961, amb una experiència d'inclusió d'estudiants estrangers en el pregrau. Fins a 2019 aquesta universitat havia graduat 2239 estudiants estrangers. Els països amb major quantitat d'estudiants graduats són Angola (129), Etiòpia (126), Vietnam (106) i Ghana (79). Les edats compreses en l'estudi van des dels 18 anys fins als 28 anys.

La selecció de les experiències es va basar en el mostreig intencional per criteri lògic (Sandoval, 1996) que implica treballar tots els casos que reuneixin algun criteri predeterminat d'importància. A més, es va seguir el criteri d'accessibilitat (Valls, 1999). Els criteris predeterminats van ser: 1) tenir com a tema de recerca les relacions interculturals des d'un enfocament psicosocial; 2) posseir com a context de recerca la UCLV; 3 ) comptar amb una data de realització menor de 5 anys; 4) comptar amb registres detallats de l'experiència; 5) qui sistematitza ha d'haver participat en la realització de l'experiència.

\section{Resultats}

Els elements constitutius del programa d'intervenció psicosocial per a promoure la integració intercultural en la UCLV van ser: els fonaments teòric-metodològics psicosocials, l'estructura organitzativa i l'avaluació. Els fonaments teòric-metodològics psicosocials del programa especifiquen les bases teòriques i metodològiques en relació amb les problemàtiques psicosocials identificades. L'estructura organitzativa estableix l'especificació operacional dels projectes a realitzar. L'avaluació del programa, detalla la planificació del procés d'avaluació al qual ha de ser sotmès i de la innovació en els moments d'avaluació inicial i final. Seguidament es descriuen els resultats de la recerca interventiva, d'acord amb cadascun d'aquests elements.

\subsection{Coalició comunitària para la promoció del treball en xarxes entre els agents institucionals i educatius}

Per a potenciar l'acció estratègica de la institució educativa com a espai d'intermediació en la promoció de la integració intercultural en la UCLV es va proposar el projecte "Coalició comunitària per a la promoció del treball en xarxes entre els agents institucionals i educatius".

La seva realització es va establir amb agents presents en el context universitari amb poder per a la presa de decisions i el maneig de recursos. Els participants previstos són: dirigents polítics i estudiantils, directiva del departament d'Atenció a Estudiants Estrangers, directiva del Departament de Comunicació, directiva del Departament d'Extensió Universitària, degans i propietaris de serveis autònoms en el context universitari.

Aquest projecte té dues fases: 1) Formació i 2) Planificació i actuació. Es consideren com a aspectes metodològics la disposició de la comunitat, la intencionalitat, l'estructura i capacitat organitzacional, l'afiliació o participació, el lideratge col-laboratiu, relacions i assistència tècnica (Martínez \& Martínez, 2003). Per a establir la disposició de la comunitat és necessari que es valori inicialment la preparació per a solucionar la problemàtica i participar en la coalició. 
Es proposa explorar la motivació dels participants, la seva història prèvia associada a la problemàtica i interessos contraposats. La consideració de la intencionalitat implica fomentar el sentit d'eficàcia en la resposta a la problemàtica. Per a això és necessari que els objectius siguin assolibles i mesurables.

La coalició ha de tenir una estructura i capacitat organitzacional sustentada en la presa de decisions compartides, la comunicació efectiva, un bon lideratge i els recursos humans i materials adequats. Respecte a les actuacions és necessari que la coalició realitzi els seus objectius i documenti els resultats. Per a afavorir la sostenibilitat s'han de visualitzar resultats i mantenir l'equilibri entre l'intercanvi d'informació, la planificació de les fases de treball, la posada en marxa d'accions i la focalització en el funcionament intern. A més, s'han d'obtenir suports externs que poden provenir de la pròpia institució.

La participació activa dels membres de la coalició és indispensable; així com la seva heterogeneïtat i la identificació de nous participants en funció dels objectius proposats. Les responsabilitats han de ser delegades gradualment per a garantir el lideratge col-laboratiu. La planificació es va orientar a la construcció de relacions personals entre els participants mitjançant el contacte continu i la concepció d'activitats per a fomentar la confiança mútua i la cooperació. Es proporciona assessoria per part dels investigadors per a donar suport al seu funcionament.

En funció de la metodologia de treball que sigui proposada i aprovada per la coalició s'assessora la realització dels espais de coordinació i diàleg per a:

- Reflexionar sobre la necessitat d'instaurar pràctiques educatives interculturals en el context universitari orientades a superar esquemes d'actuació homogeneïtzadors i que només emfatitzen el rendiment acadèmic com a criteri de diferenciació.

- Valorar a nivell estructural les condicions que afavoreixen la presència de la problemàtica com és la distribució en residències estudiantils diferenciades que soluciona dificultats d'índole organitzativa i de qualitat en l'atenció als estudiants estrangers, però té impacte en el procés integració - exclusió.

- Valorar les necessitats de mantenir la formació humanística en tots els perfils professionals, de trencar amb el formalisme, conformisme i escassa implicació personal quan es tracta del procés docent-educatiu i de desenvolupar habilitats socials i empàtiques que són la base de la moral.

- Analitzar com està continguda la interculturalitat en el Projecte Educatiu de cada any acadèmic que constitueix una de les vies fonamentals per a l'assoliment dels fins que es proposa la universitat.

\subsection{Grup d’aprenentatge per a fomentar capacitats relacionals i personals en el procés d'integració- exclusió en les relacions interculturals}

Es proposa el projecte "Grup d'aprenentatge per a fomentar capacitats relacionals i personals en el procés d'integracióexclusió en les relacions interculturals” per a la consecució del segon objectiu específic. Té com a base l'aprenentatge grupal. Se sustenta en la promoció de relacions democràtiques i treballa sobre els coneixements, actituds i habilitats. Els participants previstos són: grups escolars amb presència de diversitat aportada per l'origen cultural.

Des d'aquesta estratègia s'articulen accions basades en la hipòtesi del contacte i en la teoria de la categorització social per a la modificació de les interaccions entre els grups i els límits intergrupals. Les activitats consisteixen en la promoció de la interacció amb membres del exogrup en un entorn que estimuli la cooperació i el disseny de tasques que puguin ser realitzades amb èxit. Les estratègies basades en la teoria de la categorització social comprenen: la decategorizació (redefinir als membres d'un exogrup mitjançant la seva diferenciació i personalització), la recategorització (buscar una identitat supraordenada inclusiva) i la categorització creuada (entrecreuar les formes d'identitat social).

\subsection{Sensibilització per a produir alternatives de subjectivació davant estereotips, prejudicis i discriminació en les relacions interculturals}

Es proposa el projecte "Sensibilització per a produir alternatives de subjectivació davant estereotips, prejudicis i discriminació en les relacions interculturals” per a la consecució del tercer objectiu específic. Es va estructurar mitjançant tallers lúdics. Els participants previstos són: brigades escolars homogènies per l'origen cultural o dispositius grupals conformats per a la intervenció. 
En el disseny dels tallers de sensibilització es va considerar el treball amb materials contra-estereotípics, la dissonància cognitiva i la promoció de l'empatia per a la modificació de sentits, comportaments individuals i preparació per a l'acció col-lectiva. El treball amb materials contra-estereotípics permet fer sortint, mitjançant exemplars positius, característiques que no són estereotípics del grup. La dissonància cognitiva s'orienta a conscienciar a les persones de la inconsistència que existeix entre els prejudicis i els valors normatius d'igualtat i interculturalitat. La promoció de l'empatia s'orienta a augmentar la consciència de l'existència d'estereotips i prejudicis; així com el seu impacte en les relacions interculturals.

\subsection{A valuació del programa}

Es va planificar l'avaluació del programa en dues etapes: 1) preparació e 2) implementació a partir de la proposta de Gambara i Trujillo (2007).

\section{Avaluació de disseny}

L'avaluació de disseny es va realitzar per a la presa de decisions abans de la implementació del programa. Va permetre la introducció de millores en funció de la detecció d'insuficiències i limitacions pels avaluadors. Es va emprar el qüestionari com a instrument. Es van posar a consideració dels avaluadors els criteris proposats per Pérez-Juste (1996).

La selecció dels avaluadors es va realitzar des d'un mostreig intencional opinàtic (Ruiz-Olabuénaga, 1999) que va combinar com a criteris de selecció la conveniència i la disponibilitat. El criteri de conveniència va orientar la selecció cap a professionals de les ciències socials amb experiència docent i investigadora en la fonamentació i disseny de programes des de la perspectiva psicosocial.

Els professionals seleccionats com a avaluadors s'exercien en la UCLV; el que va brindar l'oportunitat d'una avaluació contextualitzada i enriquida a partir de les pròpies vivències i experiències en el context d'intervenció. D'aquesta manera es van seleccionar 5 avaluadors.

L'avaluació qualitativa del disseny del programa abans de la seva implementació va produir valoracions sobre les fortaleses i febleses, així com recomanacions per a fer-ho més efectiu. En considerar els criteris proposats, els avaluadors van valorar el programa com a nou, pertinent i rigorós en l'ordre teòric-metodològic. Van considerar que s'ajusta a les possibilitats institucionals actuals per a enfrontar la problemàtica diagnosticada respecte als processos inclusió-exclusió a partir de les mediacions per la subjectivitat en les relacions interculturals.

\section{Avaluació de necessitats}

Es va proposar emprar el grup de discussió com a tècnica, amb l'objectiu d'avaluar necessitats entorn de la problemàtica corresponent a cada escenari: context social, relacions intergrupals o dispositiu grupal. Les accions a realitzar són: presentar la recerca als possibles participants, facilitar la implicació a través de tècniques participatives i de discussió, obtenir informacions significatives sobre la problemàtica, així com establir una línia basi en l'expressió de la problemàtica.

Els aspectes a avaluar són: característiques sociodemogràfiques, informació sobre l'objecte d'intervenció, expressions de la problemàtica, incentius associats i conseqüències negatives, expectatives de solució, grau d'implicació emocional i recursos disponibles. L'avaluador ha de ser intern (personal implicat en el disseny i implementació del programa) i participatiu (els beneficiaris participen en el procés d'avaluació).

El processament de la informació es proposa des de la construcció i interpretació a partir del model teòric de les mediacions per la subjectivitat en el procés integració-exclusió intercultural que pot posar-se a prova i guanyar noves capacitats d'intel-ligibilitat. El judici avaluatiu a considerar és la pertinència. Quant a la innovació, en funció dels resultats es decideix si es passa a la instal-lació del programa o si es requereix innovació. Si aquesta és necessària ha de fer-se un registre detallat d'ella.

\section{Avaluació de progrés}

Per a aquesta etapa avaluativa es va proposar emprar l'observació dels processos de treball grupal, les tècniques grupals de tancament que permetin retroalimentar-se de vivències i opinions del grup, qüestionaris i completament de frases 
en finalitzar sessions. L'objectiu és avaluar el progrés de la implementació del programa. Les accions a realitzar són: actuació de monitoratge del procés d'implementació del programa per part de l'equip d'intervenció psicosocial i registre detallat del procés d'implementació.

Els aspectes a avaluar són: suport reeixit per part de la institució i el professorat; assistència dels participants previstos; suficiència, adequació i ús òptim dels recursos; funcionament de l'equip que condueix el programa; característiques de les interaccions entre l'equip i els participants; qualitat de l'organització i distribució de les activitats; participació activa, qualitat de les aportacions i la personalització dels continguts amb experiències prèvies i criteris propis.

L'avaluador és intern i participatiu. El judici avaluatiu a considerar és el progrés. La innovació es realitzarà en funció dels resultats.

\section{Avaluació de resultats $i$ d'impacte}

Per a realitzar aquest tipus d'avaluació es va proposar emprar els mètodes utilitzats en l'avaluació de progrés a més de grups de discussió amb els participants de cada projecte, una vegada conclòs. L'objectiu és avaluar els resultats i l'impacte del programa. Les accions a realitzar són: sol-licitud de retroalimentació dels participants i aplicació de qüestionaris i completament de frases per a tenir una retroalimentació individualitzada. Els indicadors de compliment d'objectius a curt, mitjà i llarg termini es presenten a continuació.

1) Indicadors de compliment d'objectius a curt termini en cada projecte:

- Definició de l'agenda de la coalició comunitària, creació d'una estructura, realització d'accions i millorament a través de l'avaluació.

- Conciliació d'objectius i necessitats amb participants del grup d'aprenentatge i construcció d'un coneixement grupal sobre la interculturalitat com a projecte.

- Foment de la confiança necessària dels participants en el projecte de sensibilització, producció de la necessitat de canvi, construcció de les necessitats formatives i generació de noves estratègies relacionals en el context social.

2) Indicadors de compliment d'objectius a mitjà termini en cada projecte:

- Articulació comunitària d'actors i recursos per a la promoció de la integració intercultural.

- Plantejament dels projectes interculturals de brigades estudiantils participants.

- Expressió de percepcions socials entorn de la diversitat cultural com a atribut inherent a les societats i d'actituds empàtiques i proactives davant l'establiment de contactes interculturals harmoniosos.

3) Indicadors de compliment d'objectius a llarg termini en cada projecte:

- Manteniment de l'actuació coalició comunitària entre els agents institucionals i educatius per a la promoció de la integració intercultural.

- Funcionament dels projectes interculturals de brigades estudiantils participants.

- Permanència en el temps d'alternatives de subjectivació davant estereotips, prejudicis i discriminació en les relacions interculturals.

L'equip avaluador és mixt (està compost tant per agents externs com interns) i participatiu. Els judicis avaluatius a considerar són: efectivitat, eficiència, viabilitat, sustentabilitat i avaluabilitat. 
Quant a la innovació, han de ser introduïdes millores teòriques i metodològiques. Si s'identifica l'assoliment de resultats no previstos, aquests han de ser avaluats. Si van existir afectacions en el compliment dels objectius s'orienta una anàlisi detallada i la proposta d'innovacions al programa per a la seva sustentabilitat. S'ha de valorar la possibilitat d'aplicació del programa en contextos amb característiques similars.

\section{Discussió i conclusions}

El model per a comprendre la discriminació com qualsevol conducta que nega als individus o grups una igualtat de tractament (Allport, 1954) va permetre mostrar conductes d'estigmatització i rebuig d'altres persones pel fet de pertànyer a uns certs grups socials en les seves transicions amb els estereotips i prejudicis debel-lades; els quals són objectivats com a evitació o superficialitat dels contactes, afavoriment a determinat grup, exigències diferenciades i estratègies d'adaptació unidireccionals.

Navas, Pumares, García, Rojas, Quadrat, Asencio i Fernández (2004) plantegen que les diferències en les estratègies d'aculturació medien la formació del prejudici en les relacions socials que s'estableixen. En la present recerca es va mostrar com una de les formes d'objectivació en el comportament social l'estratègia d'adaptació unidireccional que convergeix amb els processos d'aculturació que responsabilitzen només als forans amb la seva adaptació al context i assimilació dels patrons culturals i lingüístics.

Elprograma d'intervenció psicosocial per a la promoció dela integració intercultural concorda amb la proposta metodològica “intercultural i dialògica" de Dietz (2007, p. 36), que a nivell procedimental es tradueix en una metodologia qualitativa i exploratòria. Es va ponderar la participació dels beneficiaris en la planificació de tot el procés; aspecte que és considerat indispensable en les bones pràctiques interculturals (Alarcón \& Bustamante, 2007, citat en Rodríguez, 2019; Carnacea, 2013). A més, es van aconseguir combinar estratègies d’intervenció psicosocials en la reducció de biaixos intergrupals.

Es van construir com a problemàtiques psicosocials a intervenir, les següents: la manca d'una gestió estratègica de la institució educativa per a la promoció de la integració intercultural; la manca de capacitats relacionals i personals per a afrontar el procés d'integració-exclusió en les relacions interculturals; la manca produccions subjectives alternatives davant estereotips i prejudicis en les relacions interculturals.

Es va determinar estructurar l'actuació en tres escenaris: 1) el context social, 2) el grup escolar amb presència de diversitat per la cultura d'origen i 3) el dispositiu grupal homogeni per la cultura d'origen dels participants. La intervenció es va estructurar mitjançant tres projectes que empren com a estratègies d'intervenció psicosocial la coalició comunitària, el grup d'aprenentatge i la sensibilització.

\section{Referències bibliogràfiques}

Allport, F. (1954). The nature of prejudice. Cambridge, M.A: Addison-Wesley.

Aguado, O. T. (2004). Investigación en Educación Intercultural. Educatio Siglo XXI, 22, 39-57. Disponible en: https:// revistas.um.es/educatio/article/view/98/83.

Aguilar, M y Buraschi, D. (2012). El desafío de la convivencia intercultural. Rev. Inter. Mob. Hum., Año XX (38), $27-43$. https://doi.org/10.1590/S1980-85852012000100003.

Ander-Egg, E. (2003). Metodología y práctica del desarrollo de la comunidad. Buenos Aires: Lumen Hvmanitas.

Berry, J. (1985) Cultural psychology and ethnic psychology: A comparative analysis. In I. Reyes Lagunes y Y. H. Poortinga (Eds.), From a different perspective, 3-15. Lisse: Swets \& Zeitlinger.

Berry, J., Poortinga, Y., Segall, M., y Dasen, P. (2002) Cross-Cultural Psychology. Research and Applications. New York: Cambridge University Press.

Blanco, A. y Valera, S. (2007). Los Fundamentos de la Intervención Psicosocial. En: Blanco, A. y Rodríguez, J. Intervención Psicosocial. Madrid: Ed. Pearson. 
Blanco, A., Caballero, A., y de la Corte, L. (2005). Psicología de los Grupos. Madrid: Pearson Educación, S.A.

Bradshaw, J. (1972). A Taxonomy of Social Needs. Londres: Oxford University Press.

Butterforss, F. D., Goodman, R. y Wandersman, A. (1993). Community coalitions for prevention and health promotion. Health Education Research, 18 (3), 315-330. https://doi.org/10.1093/her/8.3.315.

Cabrera, I. I. (2011). Educación intercultural del estudiante universitario: modelo desde la labor educativa del año académico. (Tesis en opción al Grado científico de Doctor en Ciencias Pedagógicas), Universidad Central "Marta Abreu" de Las Villas, Centro de Estudios de Educación, Santa Clara.

Cabrera, I. I., Rodríguez González, D. R y Rodríguez Fleites, L. (2016). Estereotipos en las relaciones interculturales. Hacia la construcción de un modelo comprensivo desde una concepción histórico cultural de la subjetividad. Santa Clara: Feijóo.

Cabrera, I. I.; Rodríguez González, D. R y Alvarez Laureiro, R. (2020). Subjetividad, mediaciones y sociedad. En D. Pañella Álvarez \& I. I. Cabrera (coords.). Dinámicas subjetivas en la Cuba de Hoy, 7-19. La Habana: ALFEPSI.

Camara, S. (2010). Producción, explotación, acumulación y reproducción. En JP Mateo y R. Molero (Coords.), otra teoría económica es posible. Ensayos críticos de economía política . Madrid: Popular, 51-86.

Carnacea, M. Á. (2013). Catálogo de buenas prácticas en acción comunitaria intercultural en España y Europa. La puesta en valor de la experiencia. España: Fundación CEMPAI. https://doi.org/10.32473/edis-fs219-2013.

De Armas, N. (2014). La sistematización de resultados de investigaciones sobre una temática específica. Propuesta de una metodología. Revista Varela, 1 (37). Disponible en: http://revistavarela.uclv.edu.cu/articulos/rv3701.pdf.

Díaz-Gómez, A., González-Rey, F y Arias-Cardona, A.M. (2017). Pensar el método en los procesos de investigación en subjetividad. Rev. CES Psicol., 10 (1), 129-145. https://doi.org/10.21615/cesp.10.1.8.

Dietz, G. (2007). La Interculturalidad entre el "Empoderamiento" de Minorías y la "Gestión” de la Diversidad. Puntos de Vista, (12), 27-46.

Domínguez, M. (2008). Integración social de la juventud cubana hoy. Una mirada a su subjetividad. Revista argentina de Sociología, 6 (11), 74-95.

Escarbajal, A. (2010). Educación inclusiva e intercultural. International Journal of Developmental and Educational Psychology, 3 (1), 411-418.

Espinosa, A., Calderón-Prada, A., Burga, G. y Güímac, J. (2007). Estereotipos, prejuicios y exclusión social en un país multiétnico: el caso peruano. Revista de Psicología, 25 (2), pp. 295-338. https://doi.org/10.18800/psico.200702.007.

Galinsky, A. D y Moskowitz, G. B. (2000). Perspective taking: decreasing stereotype expression, stereotype accessibility, and in-group favoritism. Journal of Personality and Social Psychology, 78, 708-724. https://doi.org/10.1037/00223514.78.4.708.

Gambara, H y Trujillo, E. (2007). Evaluación de programas de intervención psicosocial. En: Blanco, A. \& Rodríguez, J. Intervención Psicosocial. Madrid: Ed. Pearson.

González-Rey, F y Mitjáns, A. (2016) Una epistemología para el estudio de la subjetividad: sus implicaciones metodológicas. Psicoperspectivas. Individuo y Sociedad, 15 (1), 5-16. https://doi.org/10.5027/psicoperspectivas-Vol15-Issue1-fulltext-667.

Hobsbawm, EJ y T. Ranger (Comps.) (1988). El invento de la tradición. Vic (Barcelona): Eumo.

Jara, O. (1994). Para sistematizar experiencias. San José de Costa Rica: Centro de Estudios y Publicaciones Alforja.

Martínez, F y Martínez, J. (2003). Coaliciones comunitarias: una estrategia participativa para el cambio social. Intervención Psicosocial, 12 (3), 251-267.

Morales, J y Huici, C. (1999). Psicología social. Madrid: McGraw-Hill. 
Morales, J., Moya, M., Gaviria, E y Cuadrado, I. (2007). Psicología Social (3 ed.). Madrid: McGraw-Hill.

Navas, M., Pumares, P., Sánchez, J., García, M., Rojas, A., Cuadrado, I. y Fernández, J. (2004). Estrategias y actitudes de aculturación: la perspectiva de los inmigrantes y de los autóctonos en Almería. Sevilla: Junta de Andalucía.

Páez, D. (2004) Relaciones intergrupales. En I. Fernández, S. Ubillos, E. Zubieta, y D. Páez (coords.) Psicología social, cultura y educación. España: Pearson Educación.

Pérez-Borroto, S., Cabrera, I. I y Rodríguez González, D. R., \& (2020). Permanencia en el tiempo de estereotipos interculturales. (122-135). En D. Pañella Álvarez \& I. I. Cabrera (coords.). Dinámicas subjetivas en la Cuba de Hoy. La Habana: ALFEPSI.

Pérez-Juste, R. (1996). Modelos de evaluación de programas. En C. Martínez (ed.), Evaluación de programas educativos. Madrid: UNED.

Pérez-Martínez, Y. (2019) Programa de acompañamiento psicosocial a personas con conducta deambulante acogidas en el Centro Provincial de Protección Social de Camagüey. (Tesis en opción al título de Máster en Intervención Psicosocial). Universidad Central "Marta Abreu" de Las Villas, Facultad de Ciencias Sociales, Santa Clara.

Plant, E. A., Devine, P. G., Cox, W. T. L., Columb, C., Miller, S. L., Goplen, J. \& Peruche, B. M. (2009). The Obama effect: Decreasing implicit prejudice and stereotyping. Journal of Experimental Social Psychology, 45, 961-964. https://doi. org/10.1016/j.jesp.2009.04.018.

Rivero-Baxter, Y. (2015). Posibilidades y contratiempos de la educación intercultural para la infancia y la adolescencia en Cuba. En E. Moras \& Y. Rivero-Baxter (). Participación cultural de la adolescencia en Cuba. Expresiones y claves para su comprensión. La Habana: UNICEF.

Rodríguez González, D. R. y Cabrera, I. I. (2019). Mediaciones por la subjetividad del autodesarrollo comunitario en las relaciones interculturales. Estudios en la Universidad Central "Marta Abreu" de Las Villas. Santa Clara: Feijóo.

Rodríguez, D. R. (2019). Programa de intervención psicosocial para la promoción de la integración intercultural en la UCLV. (Tesis en opción al título de Máster en Intervención Psicosocial). Universidad Central "Marta Abreu" de Las Villas, Facultad de Ciencias Sociales, Santa Clara.

Rothman J. y Thomas, E. (1994). Intervention research. Binghamton: The Haworth Press.

Ruiz-Olabuénaga, J. (1999). Metodología de la investigación cualitativa (2da. ed.). Bilbao: Universidad de Deusto.

Soler, JR (1985). Papel del Consejo de Sanidad de Guerra de la Generalidad de Cataluña en la Guerra Civil española. Gimbernat-Revista Catalana de Historia de la Medicina y de la Ciencia , 4 (2), 349-355.

Stephan, W. G y Finlay, K. (1999). The role of empathy in improving intergroup relations. Journal of Social Issues, 55, 729743. https://doi.org/10.1111/0022-4537.00144.

Taylor, S y Bogdan, R. (1987). Introducción a los métodos cualitativos de investigación. La búsqueda de significados. Barcelona: Paidós.

Valles, M. (1999). Técnicas cualitativas de investigación social: Reflexión metodológica y práctica social. Madrid: Síntesis. 